\title{
SCREEN-PRINTED MOLYBDENUM DISULFIDE ELECTRODES FOR ELECTROCHEMICAL SENSING OF DOPAMINE
}

\author{
${ }^{1}$ Michaela PAVLIČKOVÁ, ${ }^{2}$ Lenka LORENCOVÁ, ${ }^{1}$ Michal HATALA, ${ }^{2}$ Ján TKÁČ, ${ }^{1}$ Pavol GEMEINER \\ ${ }^{1}$ Faculty of Chemical and Food Technology, Slovak University of Technology in Bratislava, Slovakia, EU \\ michaela.pavlickova@stuba.sk \\ ${ }^{2}$ Institute of Chemistry, Slovak Academy of Sciences, Slovakia, EU
}

https://doi.org/10.37904/nanocon.2021.4332

\begin{abstract}
Two-dimensional (2D) molybdenum disulphide $\left(\mathrm{MoS}_{2}\right)$ belongs to a class of materials called transition metal dichalcogenides (TMDCs). Due to its large surface area, high biocompatibility, non-zero band-gap, structural versatility and mechanical flexibility, $\mathrm{MoS}_{2}$ can be used for next-generation sensing devices. In this work, printable high viscosity inks containing $\mathrm{MoS}_{2}$ in various ratios and ethyl cellulose (EC) as a binder were prepared. The effect of different $\mathrm{MoS}_{2}$ concentrations was investigated by measuring inks rheological properties. Structural and chemical properties of electrodes were studied by optical microscopy and SEM/EDX analysis. In addition, prepared $\mathrm{MoS}_{2} / \mathrm{EC}$ inks were screen-printed onto fluorine-doped tin oxide (FTO) coated glass substrates to develop working electrodes for electrochemical sensing of dopamine. Finally, differential pulse voltammetry measurements by applying FTO/MoS 2 sensors showed that dopamine's limit of detection (LOD) was below the micromolar level. This work marks to the potential for fast, simple and mass printing production of $\mathrm{MoS}_{2}$ sensors to detect further target analytes.
\end{abstract}

Keywords: Molybdenum disulfide, screen-printing, printed electronics, printable inks, electrochemical sensors

\section{INTRODUCTION}

Molybdenum disulfide $\left(\mathrm{MoS}_{2}\right)$ is a typical layered transition metal sulfide. Its structure consists of three stacked atom layers (S-Mo-S) held together by weak van der Waals forces [1]. MoS 2 has unique electronic, optical properties, and due to biocompatibility, high electrochemical catalytic activity, electron transfer ability and specific surface area is suitable for sensing and biosensing applications [2]. Therefore, $\mathrm{MoS}_{2}$ can be used for electrochemical detection of dopamine, glucose, tyrosine and other target analyses [2-4].

Dopamine (DA) is a neurotransmitter regulating the function of the central nervous and cardiovascular systems in the human brain. Deficiency of DA can lead to various neurological diseases, e.g. schizophrenia, Alzheimer's and Parkinson's disease. Hence, the determination of the DA concentrations is beneficial for disease diagnosis [5]. Standard sensors for detecting various analyses are prepared by modifying commercial carbon screen-printed electrodes (SPE). This step is usually performed by the drop-casting method $[2,4,6]$. A drop-casting method is defined as the process of dispersing an electrocatalytic material in a suitable solvent followed by the pipetting of the dispersion onto a working carbon electrode. The solvent evaporates, and electrocatalytic material is immobilized on the electrode surface. Although drop-casting is a simple method, it has several disadvantages, e.g. low reproducibility or uncontrollable distribution of the deposited material [7]. In contrast, printing techniques (screen-printing) have high reproducibility and the possibility to prepare various fine structures for a wide range of layer thicknesses. Rowley-Neale et al. prepared screen-printable carbon/MoS 2 inks by the modification of commercial carbon-graphite ink with MoS 2 particles. In their work, screen-printed carbon/MoS 2 working electrodes were used for electrochemical evaluation of oxygen reduction reaction (ORR) [7]. This work aims at the fast and simple preparation of printable high viscosity MoS $_{2}$ inks, 
which can be used to fabricate screen-printed $\mathrm{FTO} / \mathrm{MoS}_{2}$ sensors for dopamine detection at submicromolar level.

\section{EXPERIMENTAL SECTION}

\section{Materials}

Molybdenum disulfide $\left(\mathrm{MoS}_{2}\right)$ with particle size $\sim 6 \mu \mathrm{m}$, ethylcellulose (viscosity $22 \mathrm{cP} 5 \%$ in toluene/ethanol 80:20), terpineol ( $\geq 96 \%$, bp $213{ }^{\circ} \mathrm{C}$ ) and $\mathrm{FTO} /$ glass substrates (fluorine-doped tin oxide, $7 \Omega / \mathrm{sq}$ ) were purchased from Sigma Aldrich. Dopamine hydrochloride (DA, $\left.\mathrm{C}_{8} \mathrm{H}_{11} \mathrm{NO}_{2} . \mathrm{HCl}\right)$ and phosphate buffer (PB) components $\left(\mathrm{KH}_{2} \mathrm{PO}_{4}\right.$ and $\left.\mathrm{K}_{2} \mathrm{HPO}_{4}, \mathrm{pH} 7.0\right)$ used for electrochemical analysis were also ordered from Sigma Aldrich. All solutions were freshly prepared in ultrapure deionized water $(0.055 \mu \mathrm{S} / \mathrm{cm})$.

\section{$\mathrm{MoS}_{2}$ working electrode preparation}

The first step was the preparation of screen-printable $\mathrm{MoS}_{2}$ inks. The polymeric binder was prepared by dissolution $8 \mathrm{wt} \%$ of ethylcellulose in terpineol. Subsequently, different concentrations of $\mathrm{MoS}_{2}$ powder $(25,45$ and $60 \mathrm{wt} \%$; samples Mo-25, 45 and 60) were homogenized with a polymeric binder in a hand-held mixing unit. The second step was the screen-printing process, where prepared $\mathrm{MoS}_{2}$ inks were printed on $15 \times 20 \mathrm{~mm}$ FTO substrates and used as working electrodes (Figure 1). Before printing, FTO substrates were gradually cleaned in an ultrasonic bath using detergent, acetone and isopropyl alcohol (IPA) for 20 minutes in every solvent. Substrates were also UV-C pretreated for 20 minutes. The yellow high modulus polyester yarn mesh, with mesh count $71 \mathrm{~cm}^{-1}$ and $48 \mu \mathrm{m}$ thread diameter (PME 71-48 Y, SEFAR), was used in the screen-printing process. The deposition was performed on the manual screen-printing machine (Drucktech). After printing, $\mathrm{MoS}_{2}$ layers were left for 10 minutes for levelling and then dried in a laboratory oven at $120^{\circ} \mathrm{C}$ for 30 minutes.

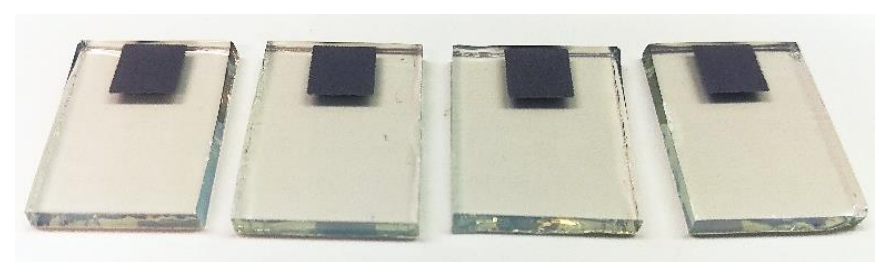

Figure 1 Image of screen-printed $\mathrm{MoS}_{2}$ working electrodes on FTO substrates for electrochemical sensing

\section{Characterization methods}

The rheological behaviour of $\mathrm{MoS}_{2}$ inks was characterized with a rheometer (HAAKE, MARS iQ) using a $35 \mathrm{~mm}$ diameter parallel plate geometry with a gap set at $0.4 \mathrm{~mm}$. The temperature was $25^{\circ} \mathrm{C}$. Dynamic viscosity $[\eta(\mathrm{Pa} . \mathrm{s})]$ and shear stress $[\tau(\mathrm{Pa})]$ were measured at a shear rate $\left[\dot{\gamma}\left(\mathrm{s}^{-1}\right)\right]$ from 0 to $2000 \mathrm{~s}^{-1}$. The level of thixotropy was characterized by time-dependent structural regeneration after shearing. Structural and chemical properties of $\mathrm{MoS}_{2}$ printed layers were analysed by optical microscopy (LEICA DM 2700 M) and scanning electron microscopy with energy-dispersive X-ray spectroscopy (SEM/EDX, JEOL JSM-IT500HR). Differential pulse voltammetry (DPV) was used for the detection of dopamine. MoS 2 layers on FTO substrates were used as working electrodes; the platinum wire was used as the counter-electrode and a argentochloride electrode $(\mathrm{Ag} / \mathrm{AgCl} / 3 \mathrm{M} \mathrm{KCl})$ as the reference electrode.

\section{RESULTS AND DISCUSSION}

In the first step, we analyzed the rheological behavior of prepared viscous and screen-printable $\mathrm{MoS}_{2}$ inks with different concentrations of $\mathrm{MoS}_{2}$. Figure 2 shows flow curve (a) and viscosity curve for typical pseudoplastic behaviour. This behaviour is characterized by decreasing dynamic viscosity with increasing shear rates and is 
crucial for the screen-printing process. It is also obvious that the structural breakdown of more concentrated $\mathrm{MoS}_{2}$ ink (Mo-60) occurs at a lower shear rate $\left(\sim 140 \mathrm{~s}^{-1}\right)$ compared to ink with $25 \mathrm{wt} \%$ of $\mathrm{MoS}_{2}\left(\sim 1170 \mathrm{~s}^{-1}\right)$. Dependence of shear stress on shear rate was measured from 0 to $1200 \mathrm{~s}^{-1}$, which corresponds to the printing process when ink is in the rest (low $\dot{\gamma}$ ) and when is pressed through the screen mesh (high $\dot{\gamma}$ ). Values of dynamic viscosity for selected shear rates: 10,100 and $400 \mathrm{~s}^{-1}$ are listed in Table1.
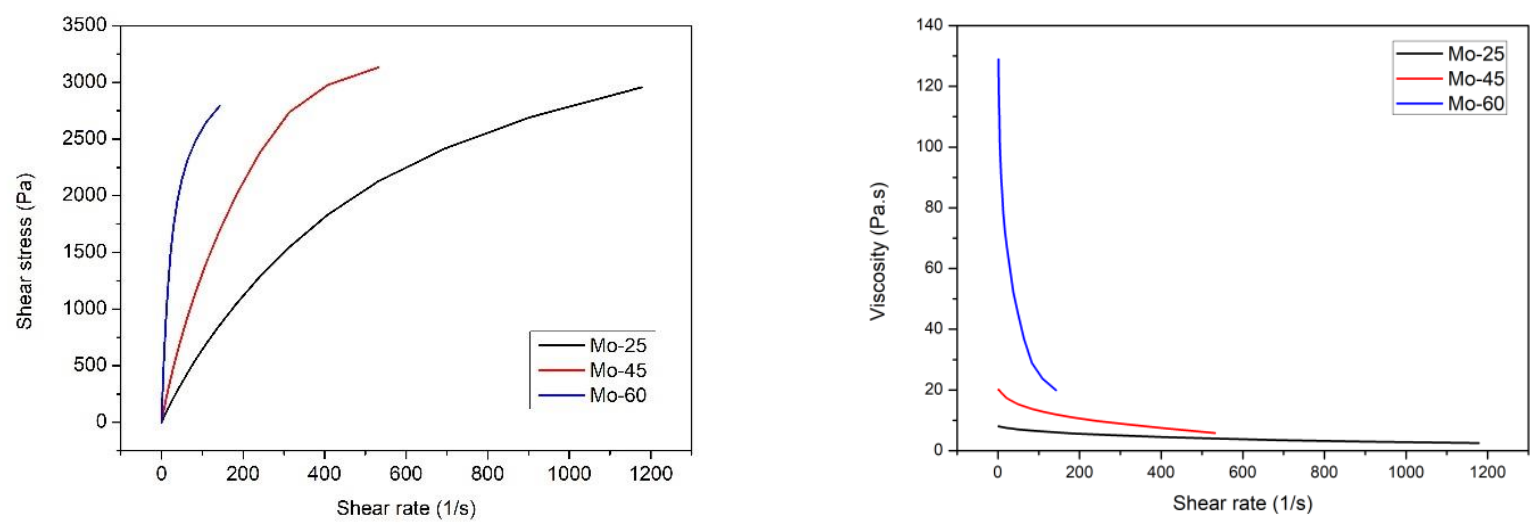

Figure 2 Flow curve (left) and viscosity curve (right) for printable inks with 25, 45 and 60 wt $\%$ of $\mathrm{MoS}_{2}$

(Mo-25, 45 and 60)

Table 1 Dynamic viscosity of screen-printable $\mathrm{MoS}_{2}$ inks at different shear rates

\begin{tabular}{cccc}
\hline & 10 & 100 & 400 \\
\hline Mo-25 & 8 & 6 & 4 \\
Mo-45 & 19 & 13 & 7 \\
Mo-60 & 85 & 24 & - \\
\hline
\end{tabular}

To investigate inks behaviour during the screen-printing process, time-dependent flow curves were measured (Figure 3). The first interval of the curve simulates behaviour at rest at a preset low shear rate $\left(0.5 \mathrm{~s}^{-1}\right)$. The second interval simulates the structural breakdown of the ink during the screen-printing process at a preset high shear rate $\left(2000 \mathrm{~s}^{-1}\right)$. The third interval simulates structural regeneration at rest after application using the same preset low shear rate as in the first interval. The recovery rates of samples Mo- 25 and Mo- 45 were 74 and $90 \%$, respectively. In the case of the sample Mo-45, viscosity regeneration was rapid from the beginning and then increased linearly (Figure $\mathbf{3}$ (a), (b)). Figure $\mathbf{3}$ (c) shows that structure of sample Mo-60 was totally destroyed after applying high shear rates, and thus viscosity regeneration could not be evaluated.

(a)

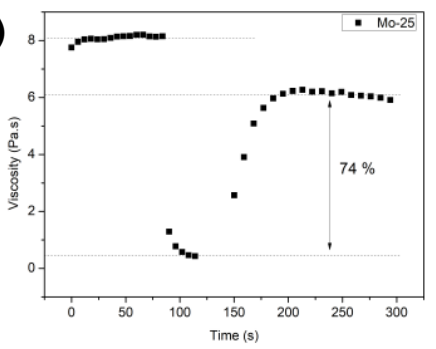

(b)

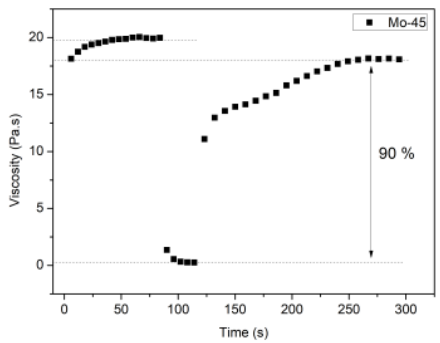

(c)

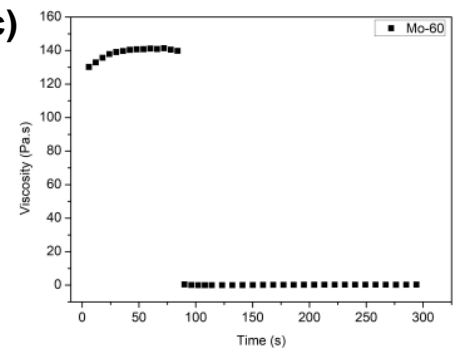

Figure 3 Comparison of the structural regeneration of inks with different $\mathrm{MoS}_{2}$ concentrations using timedependent viscosity curves; (a) 25, (b) 45 and (c) 60 wt\% $\mathrm{MoS}_{2}$ 
The structural and chemical properties of screen-printed $\mathrm{MoS}_{2}$ layers were analyzed. The thickness of screenprinted $\mathrm{MoS}_{2}$ layers was measured using an optical microscope, by a 3D image sequential recording method. The recorded values confirmed the influence of particle concentration. The thickness of layers increased with the amount of $\mathrm{MoS}_{2}$ particles (Table 2).

Table 2 Thickness of screen-printed $\mathrm{MoS}_{2}$ layers

\begin{tabular}{cccc}
\hline Sample & Mo-25 & Mo-45 & Mo-60 \\
\hline Thickness $(\boldsymbol{\mu m})$ & $4 \pm 1$ & $11 \pm 2$ & $18 \pm 1$ \\
\hline
\end{tabular}

Figure 4 shows results of SEM/EDX analysis where it can be clearly seen that the layer of sample Mo-25 is not as homogenous as thicker layers of samples with higher $\mathrm{MoS}_{2}$ content. The atomic representation of elements (atom \%) was further investigated through EDX and confirmed the presence of Sn, which is a component of FTO substrates. The atom\% of $\mathrm{C}$, which belongs to the binder, decrease with increasing $\mathrm{MoS}_{2}$ concentration (Table 3). Table 3 also shows that the atomic ratios of S/Mo are 2.4, which corresponds to $\mathrm{MoS}_{2}$ structure.
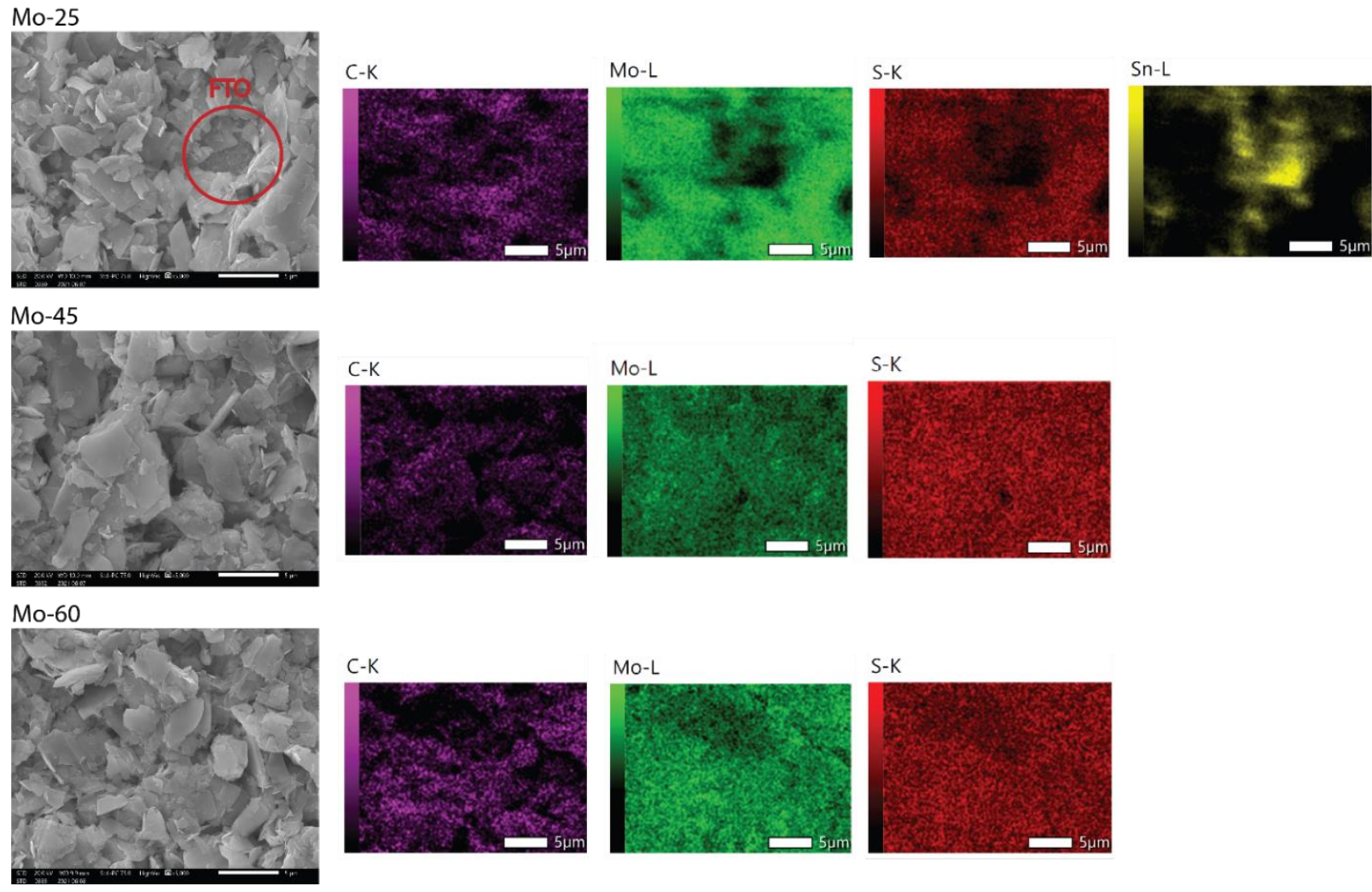

Figure 4 SEM/EDX analysis of printed Mo-25, Mo-45 and Mo-60 layers

Table 3 Atomic representation of elements in $\mathrm{MoS}_{2}$ printed layers obtained by EDX analysis

\begin{tabular}{cccc}
\hline & & Atom\% & \\
\cline { 2 - 4 } & Mo-25 & Mo-45 & Mo-60 \\
\hline C & $48.21 \pm 0.06$ & $41.35 \pm 0.06$ & $39.55 \pm 0.06$ \\
\hline S & $33.07 \pm 0.02$ & $41.53 \pm 0.02$ & $42.75 \pm 0.02$ \\
\hline Mo & $14.02 \pm 0.02$ & $17.13 \pm 0.03$ & $17.70 \pm 0.02$ \\
\hline Sn & $4.70 \pm 0.01$ & - & - \\
\hline
\end{tabular}


The electrochemical behaviour of screen-printed FTO/MoS2 electrodes was assessed by DPV experiment. The DPV curves showing electrochemical oxidation of dopamine in $0.1 \mathrm{M}$ phosphate buffer $(\mathrm{pH} 7.0)$ as a supporting electrolyte at above-mentioned manufactured FTO/MoS 2 electrodes can be clearly seen in Figure 5. The linear dependence of $i_{p}$ (oxidation peak current) vs. CDA (concentration of dopamine) was investigated in the range of $10-300 \mu \mathrm{M}$ for the measured analyte. The limit of detection (LOD) was calculated according to a signal-to-noise ratio $(S / M)=3$. The best LOD of $0.342 \mu \mathrm{M}\left(R^{2}=0.995\right)$ was evaluated for Mo45 sample. LODs of $2.1 \mu \mathrm{M}\left(R^{2}=0.996\right)$ and $1.2 \mu \mathrm{M}\left(R^{2}=0.982\right)$ were achieved for Mo-25 and Mo-60 samples, respectively.

(a)

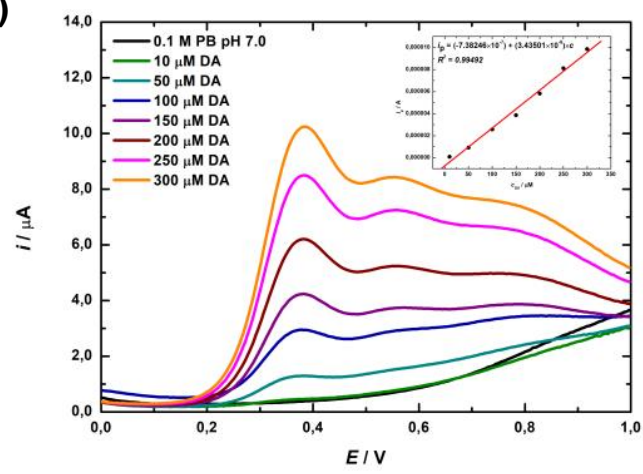

(b)

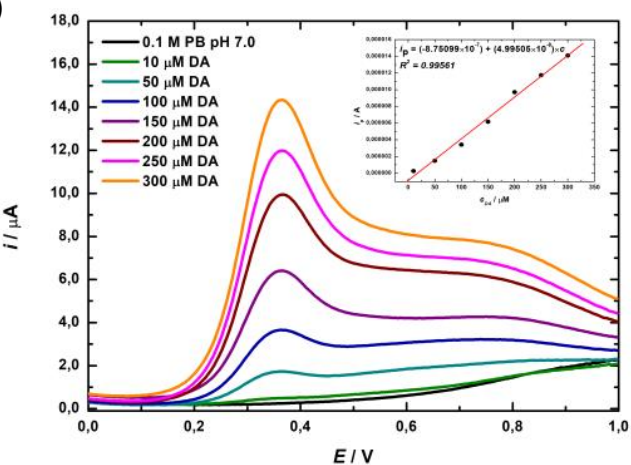

(c)

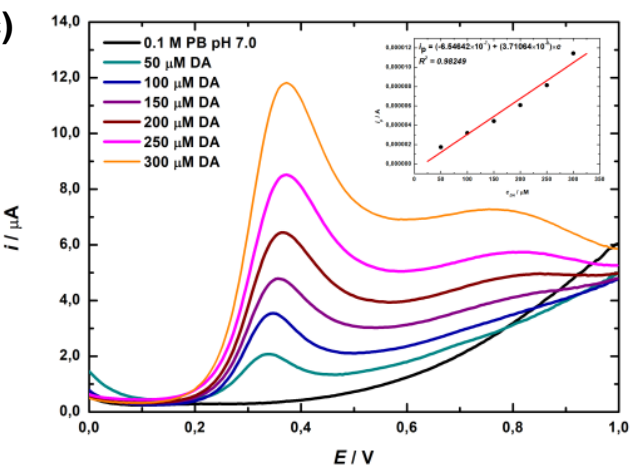

Figure 5 DPVs recorded for different concentrations of DA at Mo-25 (a), Mo-45 (b) and Mo-60 (c) in 0.1 M $\mathrm{PB} \mathrm{pH} 7.0$

\section{CONCLUSION}

In this work, printable inks were prepared containing different concentrations of $\mathrm{MoS}_{2}$ and ethylcellulose as a binder. After rheological behaviour analysis, $\mathrm{MoS}_{2}$ inks were screen-printed on substrates with a conductive FTO layer and were used as a working electrode for the electrochemical determination of dopamine. Prepared $\mathrm{MoS}_{2}$ inks exhibit pseudoplastic flow behaviour. The printable ink containing $45 \mathrm{wt} \% \mathrm{MoS}_{2}$ showed the ideal rheological properties because $90 \%$ of viscosity recovered, which is important in the screen-printing process. SEM/EDX analysis confirmed that the layer of sample Mo-45 is homogenous, and the $\mathrm{Sn}$ from FTO substrate is not present. Finally, FTO/MoS 2 working electrodes for the detection of dopamine were successfully screenprinted. The differential pulse voltammetry measurements showed that the best limit of detection of $0.342 \mu \mathrm{M}$ was evaluated for the working electrode printed from ink containing $45 \mathrm{wt} \% \mathrm{MoS}_{2}$. This work confirmed that it is possible to prepare $\mathrm{MoS}_{2}$ sensors by simple screen-printing technique and that the sensors show great potential towards detection of further target analytes. 


\section{ACKNOWLEDGEMENTS}

\section{This research was supported by the Slovak Grant Agency (VEGA 1/0488/19), the STU Grant Scheme for Support of Young Researches "GRAPHENEPRINT" and APVV-17-0300.}

\section{REFERENCES}

[1] CHENG, M., ZHANG, X.,WANG, M., HUANG, H., MA, J. A facile electrochemical sensor based on welldispersed graphene-molybdenum disulfide modified electrode for highly sensitive detection of dopamine.J. Electroanal. Chem. [online]. 2017, vol. 786, pp. 1-7. Available from: https://doi.org/10.1016/J.JELECHEM.2017.01.012.

[2] VAN TUAN, D., THUY NGAN, D.T., THUY, N.T., LAN, H., NGUYET, N.T., VAN THU, V., HUNG, V., TAM, P.H. Effect of nanostructured $\mathrm{MoS}_{2}$ morphology on the glucose sensing of electrochemical biosensors. Curr. Appl. Phys. [online]. 2020, vol. 20, no. 9, pp. 1090-1096. Available from: https://doi.org/10.1016/j.cap.2020.06.027.

[3] SOOKHAKIAN, M., BASIRUN, W.J., GOH, B.T., WOI, P.M., ALIAS, Y.Molybdenum disulfide nanosheet decorated with silver nanoparticles for selective detection of dopamine. Colloids Surfaces B Biointerfaces. [online]. 2019, vol. 176, pp. 80-86. Available from: https://doi.org/10.1016/J.COLSURFB.2018.12.058.

[4] ZRIBI, R., MAALEJ, R., MESSINA, E., GILLIBERT, R., DONATO, M.G., MARAGÓ, O.M., GUCCIARDI, P.G., LEONARDI, D.G., NERI, G. Exfoliated 2D-MoS 2 nanosheets on carbon and gold screen printed electrodes for enzyme-free electrochemical sensing of tyrosine. Sensors Actuators, B Chem. [online]. 2020, vol. 303, p. 127229. Available from: https://doi.org/10.1016/j.snb.2019.127229.

[5] YIN, A., WEI, X., CAO, Y., Li, H. High-quality molybdenum disulfide nanosheets with 3D structure for electrochemical sensing.Appl. Surf. Sci. [online]. 2016, vol. 385, pp. 63-71. Available from: https://doi.org/10.1016/J.APSUSC.2016.05.066.

[6] PARRA-ALFAMBRA, A.M., CASERO, E., VÁZQUEZ, L., QUINTANA, C., DEL POZO, M.,PETIT-DOMÍNGUEZ, M.D. MoS $_{2}$ nanosheets for improving analytical performance of lactate biosensors. Sensors Actuators, $B$ Chem. [online]. 2018, vol. 274, pp. 310-317. Available from: https://doi.org/10.1016/j.snb.2018.07.124.

[7] ROWLEY-NEALE, S.J., SMITH, G.C., BANKS, C.E.Mass-Producible 2D-MoS 2 -Impregnated Screen-Printed Electrodes That Demonstrate Efficient Electrocatalysis toward the Oxygen Reduction Reaction. ACS Appl. Mater. Interfaces. [online]. 2017, vol. 9, no. 27, pp. 22539-22548. Available from: https://doi.org/10.1021/ACSAMI.7B05104. 